\title{
Correlations between Colonization of Onion Thrips and Leaf Reflectance Measures across Six Cabbage Varieties
}

\author{
János Bálint ${ }^{1,2}$, Balázs Vince Nagy ${ }^{3,4}$, József Fail ${ }^{1 *}$ \\ 1 Department of Entomology, Faculty of Horticultural Science, Corvinus University of Budapest, Budapest, Hungary, 2 Department of Horticulture, Faculty of Technical and \\ Human Sciences, Sapientia University, Tîrgu-Mureş, Romania, 3 Department of Mechatronics, Optics and Engineering Informatics, Budapest University of Technology and \\ Economics, Budapest, Hungary, 4 Institute of Psychology, University of Sao Paulo, Sao Paulo, Brazil
}

\begin{abstract}
The main purpose of this study was to reveal if the UV-A, and visible light reflection of leaves of white cabbage varieties is correlated to resistance against onion thrips. The antixenotic resistance (AR) against onion thrips and thrips damage differed between varieties Balashi, Bloktor, Riana - considered resistant - and Green Gem, Hurricane, Quisor - considered susceptible. The solar UV-A (340-400 nm) and visible $(401-650 \mathrm{~nm})$ light reflection of white cabbage leaves were recorded. Correlation between AR against onion thrips and reflection of leaves in UV-A and visible range of the studied white cabbage varieties were computed. According to the AR evaluation onion thrips density was always higher on susceptible than on resistant varieties. The UV-A light reflection of head forming leaves and the contrast between head and exterior leaves (H/E) was negatively correlated with onion thrips host preference at an early stage of cabbage head formation. The visible light reflection of both head forming and exterior leaves was also negatively correlated with onion thrips host preference. Susceptible varieties had greater damage ratings at harvest than resistant ones and positive correlations were observed between AR and damage. AR against onion thrips may be affected by differences in reflection of cabbage leaves at an early growth stage. It is suggested that more intensive reflection of leaves and/or higher contrast values between the reflectance intensity of head versus outer leaves made the resistant varieties less attractive to onion thrips. Our results reported here provide the first evidence of negative correlation between UV-A and visible reflection of leaves and AR of white cabbage against a dangerous insect pest, opening new perspectives for understanding the role of reflection by plant leaves in pest management.
\end{abstract}

Citation: Bálint J, Nagy BV, Fail J (2013) Correlations between Colonization of Onion Thrips and Leaf Reflectance Measures across Six Cabbage Varieties. PLoS ONE 8(9): e73848. doi:10.1371/journal.pone.0073848

Editor: Murad Ghanim, Volcani Center, Israel

Received May 16, 2012; Accepted July 29, 2013; Published September 5, 2013

Copyright: (C) 2013 Balint et al. This is an open-access article distributed under the terms of the Creative Commons Attribution License, which permits unrestricted use, distribution, and reproduction in any medium, provided the original author and source are credited.

Funding: This study was financially supported by the Balassi Institute - Hungarian Scholarship Board Office and Institute for Ethnic and National Minority Studies of the Hungarian Academy of Sciences. Bakker Brothers, Bejo Zaden B.V., Daehnfeldt A/S and Syngenta Seeds Inc. are acknowledged for providing seeds for this study. Author BVN was supported by FAPESP (09/54292-7). The funders had no role in study design, data collection and analysis, decision to publish, or preparation of the manuscript.

Competing Interests: The authors have the following interest: Bakker Brothers, Bejo Zaden B.V., Daehnfeldt A/S and Syngenta Seeds Inc. are acknowledged for providing seeds for this study. There are no patents, products in development or marketed products to declare. This does not alter adherence to all the PLOS ONE policies on sharing data and materials, as detailed online in the guide for authors.

*E-mail: jozsef.fail@uni-corvinus.hu

\section{Introduction}

One of the most important pests of cabbage is the onion thrips (Thrips tabaci Lindeman, 1889) [1,2]. In the last two decades this pest has become a major problem in the summer production period [3]. Damage is produced by individuals from head forming leaves, here for susceptible varieties thrips number was twice high as on exterior leaves [4]. The most common method to control onion thrips populations is the use of foliar insecticides, but $T$. tabaci is difficult to control because insects are found mainly in the narrow spaces between the inner leaves [5-7]. The use of natural enemies (predatory mites) does not give adequate control either [8]. Other authors have stated that the primary control of onion thrips damaging cabbage may be the selection of tolerant varieties $[9,10]$. Only a few experiments have been carried out in order to assess the mechanism that determines resistance of white cabbage against onion thrips. The term antixenosis was proposed by Kogan and Ortman [11] and defines host plant features (for instance leaf structures, light reflectance, chemical volatiles) that can positively or negatively influence the colonization of phytophagous insects.
In later studies Fail et al. [12] confirmed that antixenosis plays a role in the resistance of white cabbage against onion thrips and also proposed that the leaf reflectance might have a significant role in host acceptance of onion thrips. Thus, thrips might use visual cues in deciding whether to colonize a cabbage-plant.

Insects select their host plant by visual cues between a plant and its environment [13]. For host plant recognition the most important factors are the hue (dominant wavelength reflection) the saturation (hue clearness) and the brightness [13]. Insects possess photoreceptors in their eyes that are sensitive to limited intercepts (colors) of the wavelength spectrum of solar radiation [14]. UV perception in the range of $350-390 \mathrm{~nm}$ is important for host plant detection by most insects $[15,16]$. Experiments revealed that for many thrips species the UV reflection of surfaces between 350-370 nm were repellent [13]. UV sensitivity was assessed with electro-physiological methods on Frankliniella occidentalis Pergande, 1895 and with behavioral methods on Caliothrips phaseoli Hood, $1912[17,18]$. Perception of UV was demonstrated for both species, UV-A sensibility of $F$. occidentalis and both UV-A and UVB sensitivity of $C$. phaseoli were observed [17,18]. A well- 
Table 1. Start of head formation and timetable of evaluations.

\begin{tabular}{|c|c|c|c|c|c|c|}
\hline \multirow{2}{*}{ Variety } & \multicolumn{2}{|c|}{ Cupping starts } & \multicolumn{2}{|c|}{ Antixenotic evaluation } & \multicolumn{2}{|c|}{ Damage assessment } \\
\hline & date & d.a.t.* & date & d.a.t.* & date & d.a.t.* \\
\hline Balashi & $10^{\text {th }}$ of June & 26 & $25^{\text {th }}$ of June & 41 & $11^{\text {th }}$ of August & 88 \\
\hline Bloktor & $18^{\text {th }}$ of June & 34 & $25^{\text {th }}$ of June & 41 & $10^{\text {th }}$ of October & 148 \\
\hline Green Gem & $10^{\text {th }}$ of June & 26 & $19^{\text {th }}$ of June & 35 & $12^{\text {th }}$ of August & 89 \\
\hline Hurricane & $13^{\text {th }}$ of June & 29 & $24^{\text {th }}$ of June & 40 & $17^{\text {th }}$ of September & 125 \\
\hline Quisor & $10^{\text {th }}$ of June & 26 & $19^{\text {th }}$ of June & 35 & $19^{\text {th }}$ of August & 96 \\
\hline Riana & $10^{\text {th }}$ of June & 26 & $24^{\text {th }}$ of June & 40 & $21^{\text {th }}$ of August & 98 \\
\hline
\end{tabular}

*d.a.t. = days after transplantation.

doi:10.1371/journal.pone.0073848.t001

documented phenomenon is that the intensity of host plant consumption by insects frequently increases when the UV-B solar radiation is experimentally attenuated using filters [18-21] but the relationship between UV-A reflection of leaves and antixenotic resistance $(\mathrm{AR})$ of cultivated plants against insects has not been previously addressed. Thus, thrips seem to respond to light reflectance properties, but the relationship between UV-A reflection of leaves and antixenotic resistance (AR) of cultivated plants against insects has not been previously investigated.

In this study the hypothesis that UV-A reflection may differ between white cabbage varieties was tested. More specifically the relationship between white cabbage leaves' UV-A and visible reflectance,and AR against onion thrips was experimentally assessed.

\section{Materials and Methods}

\section{Ethics Statement}

All animal work was conducted according to relevant national and international guidelines. For insects collection no permits were required since the area where onion thrips were collected did not contain any strict protected areas, and onion thrips is not under protection in Europe. Also no permits were required to use insects for experiment due to the observational nature of the data collection. Formal agreements for experiment were obtained from Corvinus University of Budapest; the study was also agreed and supported by Institute for Ethnic and National Minority Studies of the Hungarian Academy of Sciences.

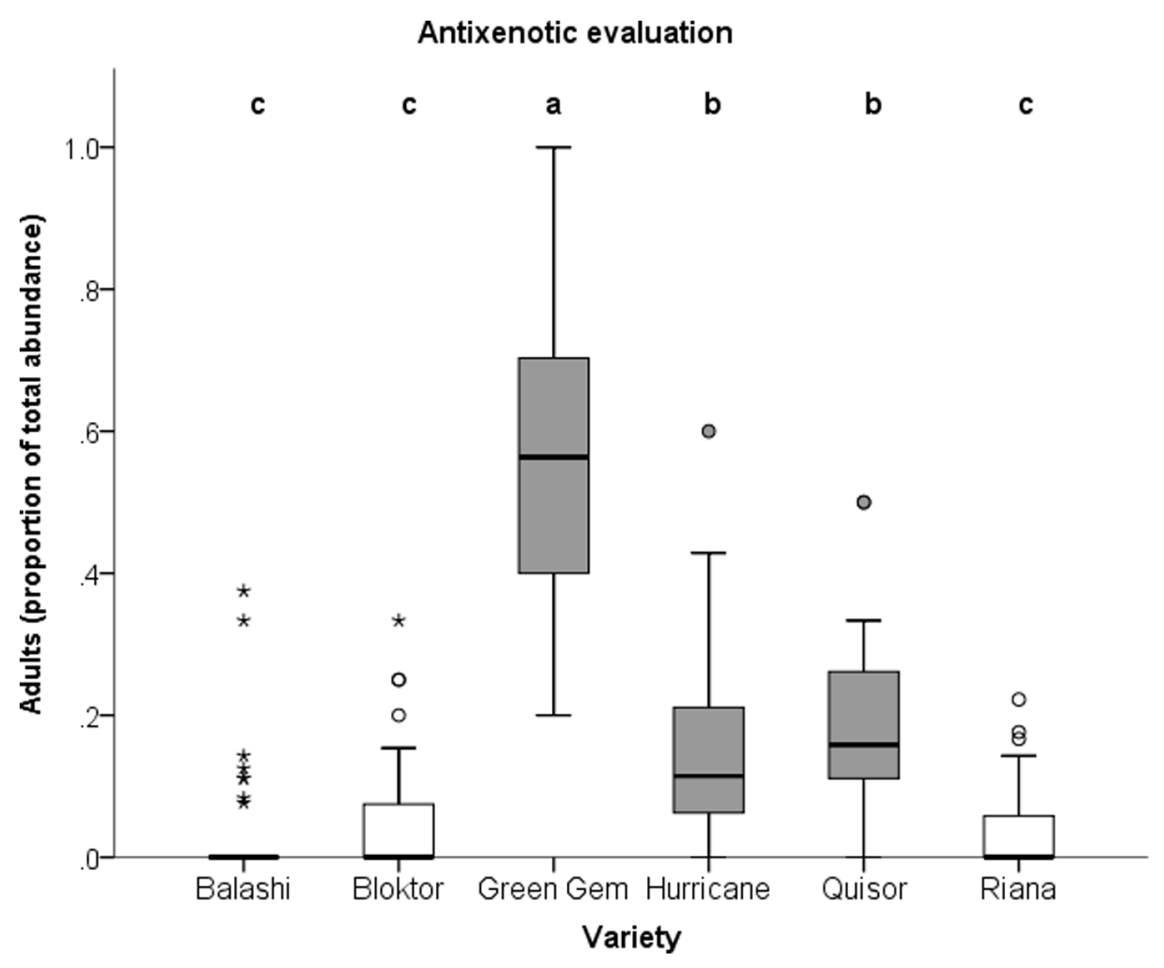

Figure 1. Antixenotic evaluation in the early stage of white cabbage head formation. Significance: Means with different letters are significantly different from each other ( $p \leq 0.01$, Mann-Whitney $U$ test). doi:10.1371/journal.pone.0073848.g001 


\section{Field Location and Experiment Design}

Six white cabbage varieties were used in the experiment. Three of these varieties (Green Gem, Hurricane and Quisor) were considered susceptible, while the other three (Balashi, Bloktor and Riana) were considered resistant to onion thrips damage [3,12]. Plants were raised at the Tordas Station of the Central Agricultural Office, Tordas, Hungary. Seedlings of $60 \times 60 \mathrm{~cm}$ distance were transplanted in May, and two blocks for each variety were established in a randomized block design each with seven rows and 13 plants in each row $(2 \times 91$ plants for each variety). Head formation started in June (Table 1).

\section{Antixenotic Evaluation}

We considered $\mathrm{AR}$ as the number of thrips colonizing white cabbage varieties at the beginning of the vegetation period during the cabbage head formation (cabbage head weight 34-114 g). Individuals already reproducing on cabbage head leaves must face biological properties too - antibiosis -, so the term antixenosis cannot be used at a later time, when newly emerged individuals on cabbage appeared. Samples consisted of 24 randomly selected cabbage heads from each block (a total of 48 sample/variety). Cabbage heads were kept in plastic bags at room temperature for a few hours in the laboratory until the antixenotic evaluation was completed. During the evaluation the first ten outer head leaves from every cabbage head were removed one by one and the number of adult thrips was counted on both upper and lower sides

\section{A}
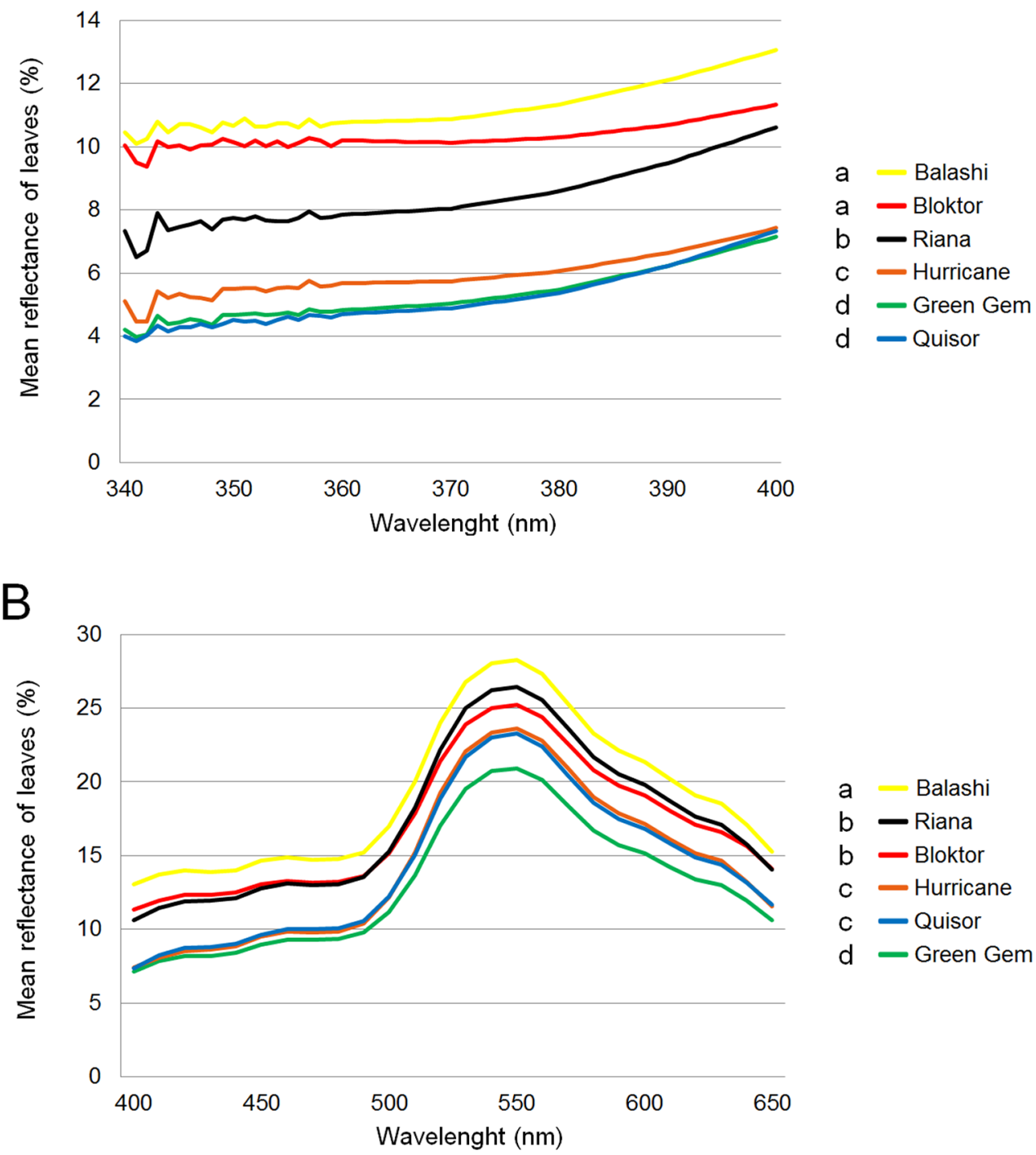

Figure 2. Reflection of head forming leaves in UV-A (A) and visible range (B) in the early period of the white cabbage head formation. Explanation: For data analyses the reflection was measured in 12 leaves four times for each variety from $340 \mathrm{~nm}$ to $650 \mathrm{~nm}$. These four values were averaged ( $n=12$ xaverage of 4 measurements/each variety). An average reflection value for each $n m$ for UV-A (340-400 nm) were computed for each leaf and a sum of 12 average reflection values were obtained for each variety. These served as quantitative variable for statistical analyses (A). The same approach between 400 to $650 \mathrm{~nm}$ was used to get values for visible range (B). Balashi, Bloktor and Riana are considered resistant, Green Gem, Hurricane and Quisor are considered susceptible to onion thrips. Significance: Means with different letters are significantly different from each other (UV-A with Games-Howell test and visible range of light by Tukey HSD test). doi:10.1371/journal.pone.0073848.g002 

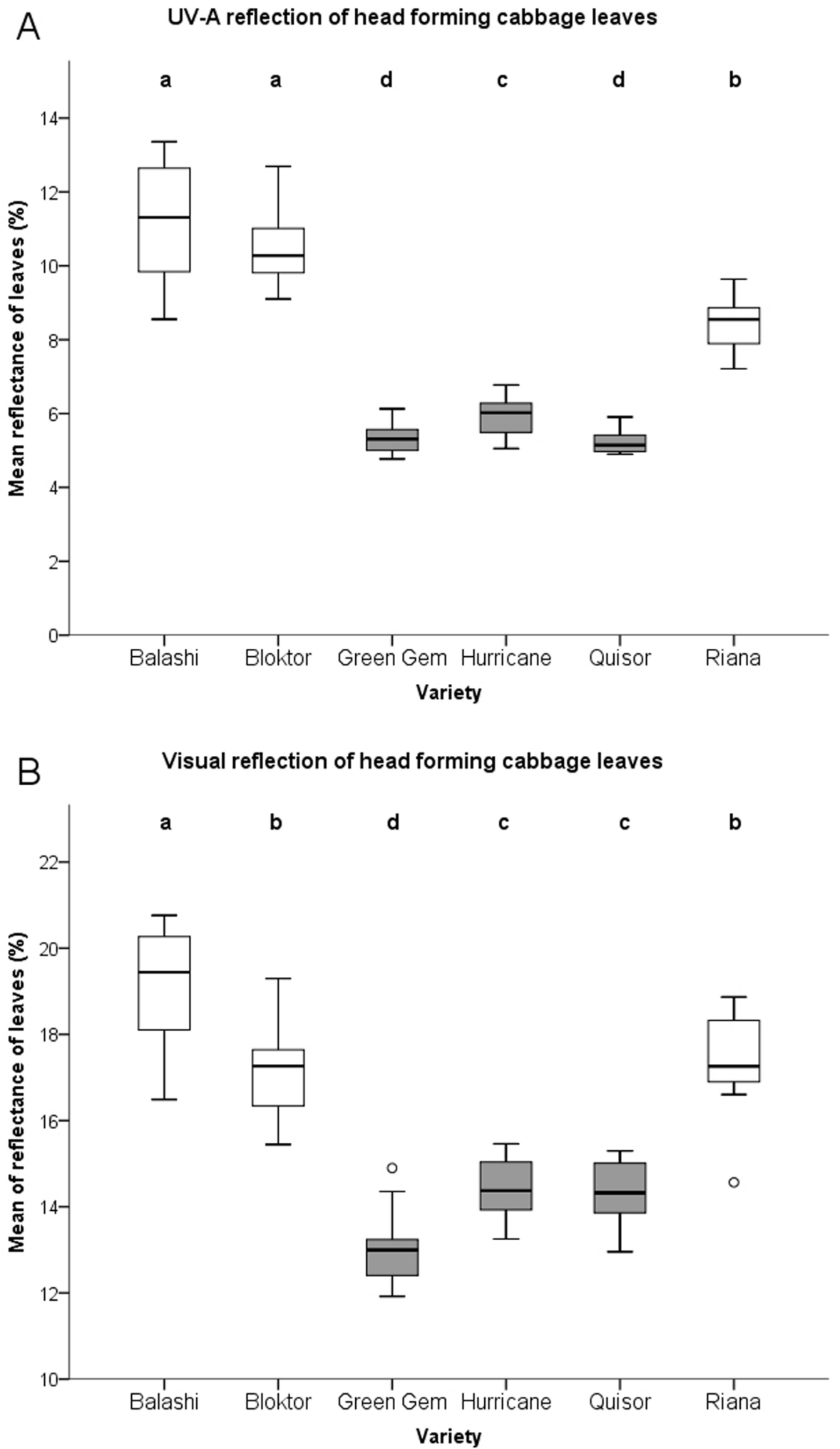

Figure 3. Reflection of head forming cabbage leaves in UV-A (A) and visible range (B). Explanation: For data analyses the reflection was measured in 12 leaves four times for each variety from $340 \mathrm{~nm}$ to $650 \mathrm{~nm}$. These four values were averaged ( $\mathrm{n}=12 \times$ average of 4 measurements/ each variety). An average reflection value for each $\mathrm{nm}$ for UV-A (340-400 $\mathrm{nm}$ ) were computed for each leaf and a sum of 12 averages of reflection values were obtained for each variety. These served as quantitative variable for statistical analyses (A). Significance: Means with different letters are significantly different from each other (UV-A with Games-Howell test and visible range of light by Tukey HSD test). doi:10.1371/journal.pone.0073848.g003 
under a stereomicroscope. Resistance cannot be defined as an absolute value, (generally it is a relative feature) so rather than use the absolute number of colonizing thrips in the analyses, the proportion of total abundance (PTA) was considered. The total number of individuals from the first sample was separately summed from each variety and the proportion of total abundance (PTA) was computed. The same calculation was done for the next samples and the values gained were used as variables in statistical analyses.

\section{Leaves Reflection Measurements}

Sample collections were made consistently for all varieties before sampling for the antixenotic evaluation. The number of replicates in each sampling event was 48 from each variety. Leaf sections of $7 \times 7 \mathrm{~cm}$ were prepared from the exterior and first head-forming leaves of 12 plants of each variety. Leaf reflection was measured in the UV-A range from 340 to $400 \mathrm{~nm}$ with $1 \mathrm{~nm}$ spectral resolution. Additionally, the visible spectral reflections from 401 to $650 \mathrm{~nm}$ with $10 \mathrm{~nm}$ spectral resolution were recorded. Because the surfaces of the leaves were not homogenous (veins, damages, epicuticular wax, etc.) thereby causing differences in the spectral parameters, each leaf section was measured in four different locations. The measurements were carried out with two different instruments although with the same method. In both cases a standard white surface with known spectral reflection was measured prior to the leaf spectral reflections. This way the results were acquired in relative units. In the UV range we used a UV fluorescent lamp to irradiate the samples exchanging the standard white surface with the test samples. In the visible range this white calibration was included in the spectrophotometer, thus the comparison was done automatically. The measurement distances were chosen in a way so that the surfaces of the measured samples were significantly larger than the areas captured within the measurement angle of the instruments. With this adjustment also the background of the samples was neglected. Mean values of these four measurements were generated from all data points and used for analyses. Calibrated spectrophotometer (Konica Minolta CM-2600d) and spectroradiometer (AvaSpec-2048) were used to set up and accomplish the laboratory procedure for measuring leaf reflection in the UV-A and visible range. In case of spectroradiometric measurement the illumination of the leaves was provided by a specific fluorescent lamp, with significant UV-A emission between 340 and $400 \mathrm{~nm}$.

\section{Onion Thrips Damage Assessment at Harvest}

Assessment was carried out at harvest maturity for all varieties. Similarly to the antixenotic evaluation, 24 randomly selected cabbage heads were collected from each block. To estimate thrips damage an evaluation method was adapted using the methodology developed by Fail [3]. Cabbage head leaves were evaluated and peeled off one by one until no damage was found on four consecutive leaves. During this procedure the extent of damage was assessed for every examined head-forming leaf, expressing the proportion of damaged surface to the entire surface of the leaf. A scale from 0 to 1 with an accuracy of 0.1 was used where 0 means no damage and 1 means $100 \%$ damage. The cumulated value of damage ratios noted for every examined leaf in one cabbage head and the total number of damaged leaves in a given cabbage head was considered for data analysis.

\section{Data Analysis}

A general linear model was used to test the block effects of PTA, total damaged leaf surface and number of damaged leaves using $\mathrm{R}$ language and environment. Residuals of the models were tested for normality and homogeneity of variance using package "geepack" geeglm function (Fit Generalized Estimating Equations - GEE) [22-24]. A similar general linear model was used to test the block effects of reflections using glm function [22]. PASW was used to test the proportion of total abundance and damage assessments. These data did not meet the assumption of normality, therefore the nonparametric Kruskal-Wallis test was used, followed by Mann-Whitney $\mathrm{U}$ tests to compare the varieties. For each variety in 12 external leaves the UV-A reflection between $340-400 \mathrm{~nm}$ was measured four times $(\mathrm{n}=12 \times$ average of 4 measurements/each variety). Then for each leaf a spectral average was computed from the reflection values of each nanometer between $340-400$. In this way a sum of 12 average UV reflection values were obtained for each variety. These served as quantitative variable for statistical analyses. The same approach was followed to get the quantitative variable between $400-650 \mathrm{~nm}$. The whole protocol was replicated for head forming leaves and the same variables in UV and visible range were obtained. To compare reflections the homogeneity of variances were tested with Levene test. UV-A data were not homogenous therefore the GamesHowell test was used while in visible range of light due to data homogeneity the Tukey HSD test was computed (PASW Statistics 18). Spearman's rank correlation coefficient was calculated between mean values of reflection and PTA as well as between the contrast in reflectance of head forming and exterior cabbage leaves and PTA. Correlation between the number of adult thrips and damage assessed at harvest were similarly computed using PASW Statistics 18.

\section{Results}

\section{Antixenotic Evaluation}

Statistics revealed that here was no varietal block effect $(p=0.13)$. The AR assessment yielded significant differences between the studied cabbage varieties Significantly more thrips adults were found on susceptible varieties (Green Gem, Quisor and Hurricane) than on those varieties (Bloktor, Riana and Balashi) that were categorized resistant in previous studies [12] (Figure 1). The Spearman's rank correlation between number of thrips and weight of cabbage revealed no significant positive correlation $(\mathrm{n}=288$, rho $=-0.116, \mathrm{p}=0.09)$.

\section{Leaves Reflection}

Statistics revealed no varietal block effect in UV-A reflection of head forming leaves $(p=0.83)$ and visible reflection of head forming leaves $(p=0.61)$. Significant differences in UV-A reflec-

Table 2. Spearman's rank correlation between mean reflection (UV-A and visible) and proportion of total abundance (PTA) values $(n=6)$.

\begin{tabular}{lccc}
\hline \multicolumn{4}{l}{ Spearman's correlation between UV-A and PTA } \\
\hline Head forming leaves & Exterior leaves & Contrast H/E & \\
\hline rho & $\mathbf{- 0 . 8 8 6}$ & -0.371 & $\mathbf{- 0 . 8 2 9}$ \\
Sign & $\mathbf{0 . 0 1 9}$ & 0.468 & $\mathbf{0 . 0 4 2}$ \\
Spearman's correlation between visible range and PTA & \\
rho & $\mathbf{- 1 . 0 0 0}$ & $\mathbf{- 0 . 8 2 9}$ & -0.543 \\
Sign & $\mathbf{0 . 0 1}$ & $\mathbf{0 . 0 4 2}$ & 0.266 \\
\hline
\end{tabular}

Significances are in bold.

doi:10.1371/journal.pone.0073848.t002 

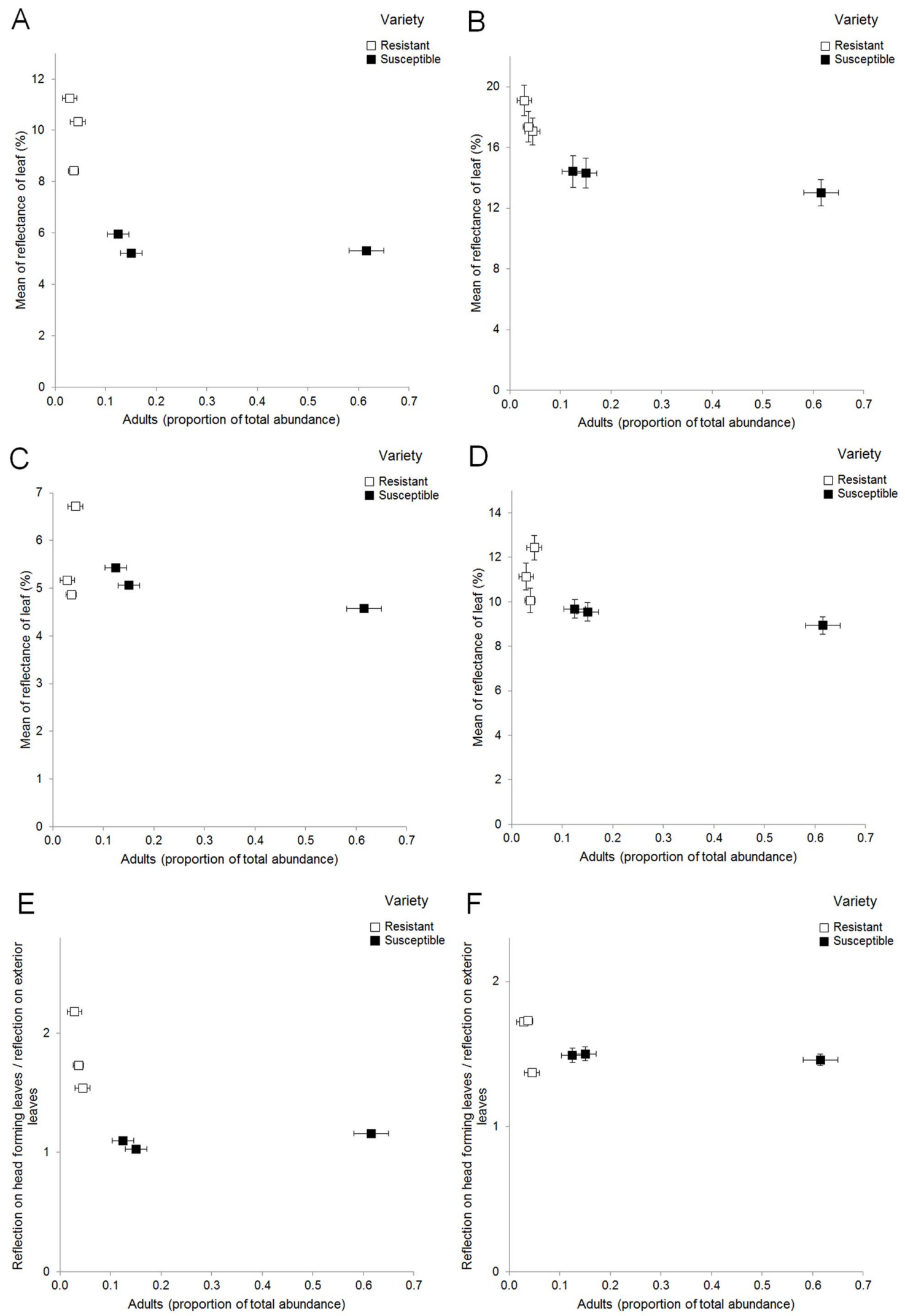

Figure 4. Plots between mean reflection (UV-A and visible) and antixenotic resistance values. A - UV-A reflection on head forming leaves and PTA, B - Visual reflection on head forming leaves and PTA, C - UV-A reflection on exterior leaves and PTA, D - Visual reflection on exterior leaves and PTA, E - Contrast UV-A reflection and PTA, F - Contrast Visual reflection and PTA.

doi:10.1371/journal.pone.0073848.g004 
tion of head forming leaves were observed between resistant varieties and also between resistant and susceptible ones (Figure 2A, Figure 3A). The mean visible reflection was also different between resistant and susceptible varieties (Figure 2B, Figure 3B). Negative correlation was detected between UV-A reflection of head forming leaves and PTA, as well as between the UV-A brightness contrast of exterior and head forming leaves and PTA in the early stage $(34-114 \mathrm{~g})$ of white cabbage head formation. The mean visible reflection of both head forming and exterior leaves was also in negative correlation with mean PTA in the early stage of the cabbage head development. No correlation between UV-A reflection of exterior leaves only and PTA or between contrast in visible range and PTA were detected (Table 2, Figure $4 \mathrm{~A}-\mathrm{F}$ ).

\section{Onion Thrips Damage Assessment at Harvest}

Statistics revealed no varietal block effect in thrips damage $(p=0.87)$ and number of damaged leaves $(p=0.82)$. Hurricane was damaged the most by thrips considering both the total number of damaged leaves and the extent of damaged leaf surface. Green Gem and Quisor also suffered significantly greater damage than any of the resistant varieties. Considerably less damage was observed on resistant varieties (Bloktor, Balashi and Riana) (Table 3). Highly positive correlation was observed between number of adult thrips and damage at harvest maturity $(\mathrm{n}=288$, Spearman's rho $=0.541, \mathrm{p}<0.001)$.

\section{Discussion and Conclusion}

Results in concordance with other studies support the idea that the antixenotic resistance of white cabbage against a polyphagous pest such as onion thrips does exist. The onion thrips density was always higher on susceptible (Green Gem, Hurricane, Quisor) than on resistant varieties (Balashi, Bloktor, Riana). Similar studies evaluated the number of thrips on both exterior and head forming leaves [25], but we only made assessment on head forming leaves because these individuals are responsible for damage that appears as a consequence of the plant's reaction to thrips feeding. Colonization from exterior leaves however may be possible before thrips become trapped by head leaves. Altogether the antixenotic evaluation based on colonizing thrips adults at the beginning of cabbage head formation can be considered an appropriate method of comparing different white cabbage varieties.

Results also suggest that thrips numbers and damage were differentially associated with different reflectance values. Reflectance of white cabbage leaves may be defined as one important physical factor that plays a role in AR. Kirk [26] found similar results using color traps and reported that UV reflecting white color traps were ten times less attractive to onion thrips than white traps without UV reflectance. The phenomenon was also observed on one other thrips species too, where the repelling effect of UV reflecting metalized mulch was used against Frankliniella occidentalis (Pergande, 1895) [27]. Cabbage plants surrounded by UV reflecting metalized mulch in comparison with standard black soil coverage were less attractive for thrips [27]. In our studies negative correlation was observed between PTA and UV-A reflection and visual reflection of head forming leaves. Also negative correlation was detected between PTA and UV-A contrast and visible reflection of both head forming and exterior leaves in the early stage of white cabbage head formation (Table 2). These results altogether suggest that $\mathrm{AR}$ against onion thrips may be at least partly determined by differences in reflection of cabbage leaves at an early growth stage. The lower reflectance of head forming leaves alone or in contrast with brighter exterior leaves may attract onion thrips to invade the head leaves of susceptible varieties to a greater extent.

Similar studies reported strong positive correlation between the colonization of adult thrips and the damage ratings [12]. We can confirm this with the present work, observing that susceptible varieties suffered higher damage at harvest than resistant ones and again highly positive correlations were observed between number of adult thrips and damage.

In summary we can conclude that white cabbage leaves' UV and visible reflection might play a role in attracting thrips to colonize cabbage head leaves and as a consequence these thrips individuals cause direct damage.

\section{Author Contributions}

Conceived and designed the experiments: JF. Performed the experiments: JB JF BVN. Analyzed the data: JB BVN JF. Contributed reagents/ materials/analysis tools: JB BVN JF. Wrote the paper: JB JF.

Table 3. Damage assessment at harvest considering the mean number of damaged leaves and total damaged leaf surface.

\begin{tabular}{|c|c|c|c|c|c|c|c|c|c|}
\hline \multicolumn{5}{|c|}{ Number of damaged leaves } & \multicolumn{5}{|c|}{ Total damaged leaf surface $(1,0=1$ leaf surface $)$} \\
\hline Variety & $\begin{array}{l}\text { Date of } \\
\text { assessment }\end{array}$ & Meanc & $\mathbf{a}^{\mathbf{a}}$ & $\begin{array}{l}95 \% \\
\text { Conf. }^{b}\end{array}$ & Variety & $\begin{array}{l}\text { Date of } \\
\text { assessment }\end{array}$ & Meanc & $a^{a}$ & $\begin{array}{l}95 \% \\
\text { Conf. }^{b}\end{array}$ \\
\hline Hurricane & $17 / 09$ & 14.6 & a & 1.2 & Hurricane & $17 / 09$ & 4.0 & a & 0.3 \\
\hline Green Gem & $12 / 08$ & 8.8 & $\mathrm{~b}$ & 0.8 & Green Gem & $12 / 08$ & 2.1 & $\mathrm{~b}$ & 0.3 \\
\hline Quisor & $19 / 08$ & 6.8 & $\mathrm{c}$ & 0.5 & Quisor & $19 / 08$ & 1.6 & $\mathrm{c}$ & 0.2 \\
\hline Bloktor & $10 / 10$ & 4.4 & $d$ & 0.5 & Bloktor & $10 / 10$ & 0.8 & $d$ & 0.1 \\
\hline Balashi & $11 / 08$ & 1.0 & $\mathrm{e}$ & 0.2 & Balashi & $11 / 08$ & 0.1 & $\mathrm{e}$ & 0.0 \\
\hline Riana & $21 / 08$ & 0.5 & $f$ & 0.2 & Riana & $21 / 08$ & 0.0 & $f$ & 0.0 \\
\hline
\end{tabular}

${ }^{a}$ Significance: Means with different letters are significantly different from each other ( $p \leq 0.01$, Mann-Whitney $U$ test).

${ }^{b} 95 \%$-confidence interval of means.

${ }^{\mathrm{C}}$ Means are presented in decreasing order.

Resistant varieties are in bold.

doi:10.1371/journal.pone.0073848.t003 


\section{References}

1. Trdan S, Žnidarčič D, Kač M, Vidrih M (2008) Yield of early white cabbage grown under mulch and non-mulch conditions with low populations of onion thrips (Thrips tabaci Lindeman). Int J Pest Manage 54: 309-318.

2. Trdan S, Valič N, Žnidarčič D (2007) Field efficacy of deltamethrin in reducing damage caused by Thrips tabaci Lindeman (Thysanoptera: Thripidae) on early white cabbage. J Pest Sci 80: 217-223.

3. Fail $\mathrm{J}$ (2005) Onion Thrips damage on white cabbage, $\mathrm{PhD}$ thesis. Corvinus University of Budapest. 128 p.

4. Stoner KA, Shelton AM (1988) Influence of Variety on Abundance and WithinPlant Distribution of Onion Thrips (Thysanoptera: Thripidae) on Cabbage. J Econ Entomol 81: 1190-1195.

5. Andaloro JT, Hoy CW, Rose KB, Shelton AM (1983) Evaluation of Insecticide Usage in the New York Processing-Cabbage Pest Management Program. J Econ Entomol 76: 1121-1124.

6. Shelton AM, Nyrop JP, North RC, Petzoldt C, Foster R (1987) Development and Use of a Dynamic Sequential Sampling Program for Onion Thrips., Thrips tabaci (Thysanoptera: Thripidae), on Onions. J Econ Entomol 80: 1051-1056.

7. Diaz-Montano J, Fuchs M, Nault BA, Fail J, Shelton AM (2011) Onion Thrips (Thysanoptera: Thripidae): A Global Pest of Increasing Concern in Onion. J Econ Entomol 104: 1-13.

8. Hoy CW, Glenister CS (1991) Releasing Amblyseius spp. [Acarina: Phytoseiidae] to control Thrips tabaci [Thysanoptera: Thripidae] on cabbage. Entomophaga 36: 561-573.

9. Stoner KA, Shelton AM (1988) Effect of Planting Date and Timing of Growth Stages on Damage to Cabbage by Onion Thrips (Thysanoptera: Thripidae). J Econ Entomol 81: 1186-1189.

10. Shelton AM, Wilsey WT, Schmaedick MA (1998) Management of Onion Thrips (Thysanoptera: Thripidae) on Cabbage by Using Plant Resistance and Insecticides. J Econ Entomol 91: 329-333.

11. Kogan M, Ortman EF (1978) Antixenosis - A New Term Proposed to Define Painters Nonpreference Modality of Resistance. Bull Ecol Soc Am 24: 175-176.

12. Fail J, Zana J, Pénzes B (2008) The role of plant characteristics in the resistance of white cabbage to onion thrips: Preliminary results. Acta Phytopathol Entomol Hung 43: 267-275.

13. Terry LI (1997) Host selection, communication and reproductive behaviour. In: Lewis T, editor. Thrips as crop pests. 65-118.
14. Vernon RS, Gillespie DR (1990) Spectral Responsiveness of Frankliniella occidentalis (Thysanoptera: Thripidae) Determined by Trap Catches in Greenhouses. Environ Entomol 19: 1229-1241.

15. Briscoe AD, Chittka L (2001) The Evolution of Color Vision in Insects. Annu Rev Entomol 46: 471-510.

16. Möller R (2002) Insects Could Exploit UV-Green Contrast for Landmark Navigation. J Theor Biol 214: 619-631.

17. Matteson N, Terry I, Ascoli-Christensen A, Gilbert C (1992) Spectral efficiency of the western flower thrips, Frankliniella occidentalis. J Insect Physiol 38: 453459.

18. Mazza CA, Zavala J, Scopel AL, Ballaré CL (1999) Perception of solar UVB radiation by phytophagous insects: Behavioral responses and ecosystem implications. Proc Natl Acad Sci U S A 96: 980-985.

19. Mazza CA, Izaguirre MM, Zavala J, Scopel AL, Ballaré CL (2002) Insect perception of ambient ultraviolet-B radiation. Ecol Lett 5: 722-726.

20. Bothwell ML, Sherbot DMJ, Pollock CM (1994) Ecosystem Response to Solar Ultraviolet-B Radiation: Influence of Trophic-Level Interactions. Science 265: 97-100.

21. Mazza CA, Boccalandro HE, Giordano CV, Battista D, Scopel AL, et al. (2000) Functional Significance and Induction by Solar Radiation of UltravioletAbsorbing Sunscreens in Field-Grown Soybean Crops. Plant Physiol 122: 117126.

22. R Core Team (2012) R: A Language and Environment for Statistical Computing. R Foundation for Statistical Computing, Vienna, Austria. ISBN 3-900051-07-0. Available: http://www.R-project.org. Accessed $7^{\text {th }}$ June 2013.

23. Højsgaard S, Halekoh U, Yan J (2006) The R Package geepack for Generalized Estimating Equations. J Stat Softw 15: 1-11.

24. Yan J, Højsgaard S (2012) Generalized Estimating Equation Package. R-News. 5-8 p.

25. Stoner KA, Shelton AM (1988) Role of Nonpreference in the Resistance of Cabbage Varieties to the Onion Thrips (Thysanoptera: Thripidae). J Econ Entomol 81: 1062-1067.

26. Kirk WDJ (1984) Ecologically seIective coIoured traps. Ecol Entomol 9: 35-41.

27. Momol MT, Funderburk JE, Olson S, Stavisky J (2002) Management of tomato spotted wilt tospovirus (TSWV) on tomatoes with UV-reflective mulch and Acibenzolar-Smethyl. Thrips and Tospoviruses: Proceedings of the 7 International Symposium on Thysanoptera, Australian National Insect Collection, Canberra: 111-116. 